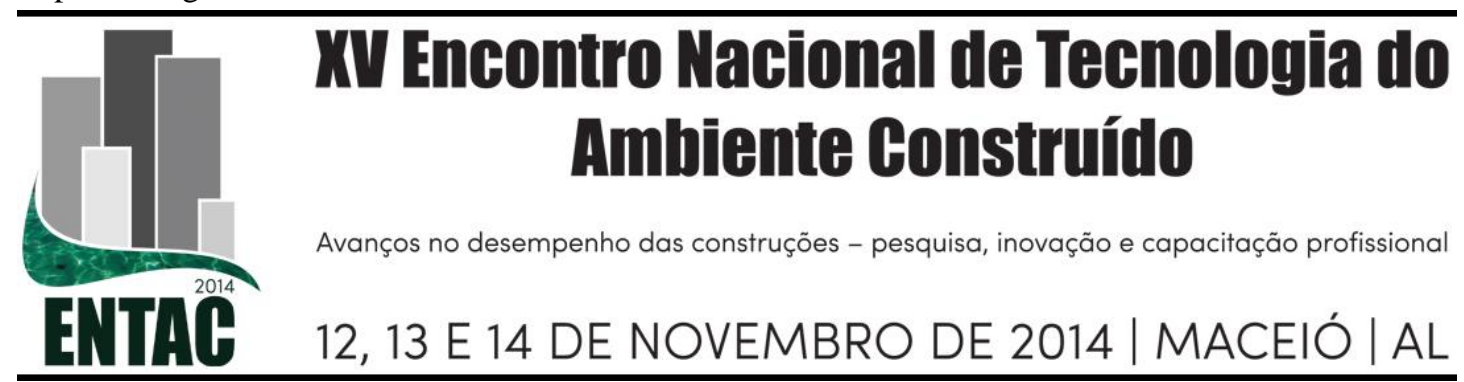

\title{
APLICAÇÃO DO MÉTODO DA LINHA DE BALANÇO EM OBRAS INDUSTRIAIS: ESTUDO DE CASO NA PETROBRAS/LUBNOR
}

\author{
CARNEIRO, Juliana Quinderé (1); CÂNDIDO, Luis Felipe (2); BARROS NETO, \\ José de Paula (3)
}

(1) AVAL Engenharia, e-mail: juliana@ avalengenharia.eng.br (2) PEC/UFC, e-mail: luisf_civil@yahoo.com.br, (3) GERCON/UFC, e-mail: jpbarros@ufc.br

\begin{abstract}
RESUMO
O planejamento de obras de grande porte vem se tornando cada vez mais importante com o intuito de diminuir os desperdícios e cumprir os prazos e os custos estimados. O objetivo desse trabalho é analisar a aplicação do método da Linha de Balanço em obras da indústria do petróleo. Para isso, utilizou-se do estudo de caso para análise de uma construção de um tanque de armazenamento de Cimento Asfáltico de Petróleo (CAP), da refinaria Petrobras/Lubnor. Foram elaborados dois cronogramas com a utilização da ferramenta de Linha de Balanço. O primeiro foi chamado de LB 1T, englobando a construção de 1 tanque de armazenamento de CAP, onde é retratado o caso da Petrobras/Lubnor. O segundo cronograma foi feito como sugestão para comparação. Trata-se da simulação da construção de 3 tanques e foi nomeado de LB 3T. Com os resultados da pesquisa foi concluído que a aplicação dessa técnica pode ser viável, desde que se encontre uma unidade de repetição que justifique a sua escolha.
\end{abstract}

Palavras-chave: Linha de Balanço, Estrutura Analítica de Projeto, Refinaria, Tanque de Armazenamento de Cimento Asfático de Petróleo, Planejamento.

\begin{abstract}
The planning of major projects is becoming more important in order of decreasing waste and attending time and costs. The aim of this study is to analyze the application of the method of the Line of Balance $(L O B)$ in projects in the petroleum industry. For this, it was chosen the case study methodology in a project of Petrobras/Lubnor Refinery. The selected project was the construction of a Asphalt Cement Storage Tank. Two schedules were prepared using the LOB tool. The first is called the LOB 1T, comprising the construction of one storage tank, where it is describe the case of Petrobras/Lubnor. The second schedule was done as a suggestion for comparison. It is the construction of 3 tanks and it was identified LOB 3T. With the survey results it was concluded that the application of this technique may be usable, provided that there is a repeating unit that justifies its choice.
\end{abstract}

Keywords: Line of Balance, Work Breakdown Structure, Refinery, Asphalt Cement Storage Tank, Planning.

\section{INTRODUÇÃO}

Com o cenário de um mundo globalizado e o aumento significativo da concorrência, o gerenciamento de projetos ganhou importância significativa. A utilização apropriada de boas práticas, de ferramentas e de técnicas de gerenciamento de projetos vem trazendo resultados positivos na busca dos objetivos das organizações (CARNEIRO, 2009).

Neste cenário, empreendimentos de grande porte, principalmente aqueles realizados com a aplicação de dinheiro público, merecem uma maior atenção quando o tema é 
planejamento. Além do alto custo, esses projetos trazem uma complexidade operacional inerente, devido à sua magnitude, em termos de quantidade de serviços, recursos financeiros aplicados e quantidade de stakeholders.

No Brasil, dentre os principais empreendimentos de grande porte, pode-se destacar aqueles realizados pela indústria petroquímica cuja principal empresa do mercado nacional é a Petrobras. Em entrevista à Rydlewski (2012), a atual presidente da Petrobras menciona que atrasos estão sendo frequentes nas obras da empresa citando o como exemplo a Refinaria Abreu e Lima em Pernambuco, que durou três anos além do prazo e custou nove vezes mais do que o previsto.

Especificamente em Fortaleza, CE a Petrobras possui uma planta de refino: a Lubrificantes e Derivados de Petróleo do Nordeste (Petrobras/Lubnor). No ano de 2012, a Petrobras/Lubnor processou 7,8 mil barris/dia (ANP, 2013) estando entre os maiores contribuintes do Estado em recolhimento de Imposto sobre a Circulação de Mercadorias e Serviços (ICMS).

Além da Petrobras/Lubnor, uma nova refinaria será instalada no estado do Ceará, denominada Refinaria Premium II, e terá capacidade para processar 300.000 barris de petróleo por dia. Segundo a Petrobras, a Premium II receberá investimento de US\$ 8,5 bilhões e será uma das maiores refinarias de petróleo do mundo, com previsão de início de operação para dezembro de 2017.

Assim, observado a situação e a importância do tema abordado, o presente trabalho tem como objetivo verificar, por meio de um estudo de caso, o potencial da utilização da ferramenta Linha de Balanço (LB) para o planejamento de obras da indústria do petróleo, o que não é fato comum no Brasil, já que há uma predominância de aplicações desta ferramenta para o planejamento de edificações.

\section{LINHA DE BALANÇO}

A LB é uma técnica utilizada para o planejamento e programação de projetos repetitivos que tem por objetivo realizar uma programação de trabalho com a utilização contínua e ininterrupta dos seus recursos (DAMCI; ARDITI; POLAT, 2013).

Sua origem encontra-se na indústria manufatureira da década de 1940. Sua criação é atribuída a Goodyear Tire and Rubber Company tendo sido desenvolvida intensamente pela marinha americana durante a segunda guerra mundial (AL SARRAJ, 1990; SUHAIL; NEALE, 1994).

A respeito de sua utilização na construção, Suhail e Neale (1994) relatam que suas primeiras aplicações deram-se no Reino Unido, aplicadas à projetos habitacionais repetitivos pela Agência Nacional de Habitação. Outras versões de suas origens são encontradas na literatura, sendo a mais divergente delas a apresentada por Sousa e Monteiro (2011) que relatam que a primeira utilização de uma técnica semelhante ao que hoje é definido como LB foi na década de 30, na construção do Empire State Building. No Brasil, a LB vem sendo aplicada desde a década de 1980, tornando-se comum nos canteiros de obra a partir da década de 1990 (HEINECK, 1996).

A LB destaca-se por ser uma ferramenta visual que permite a visualização do fluxo e outras características relevantes de um projeto repetitivo, tais como: tempo, local de trabalho, tipo de atividade, lead time, tempo de ciclo, sincronia, paralelismo, trabalho em progresso, sequência, trajetória, buffer, interferências e trabalho completo (LUCKO; ALVES; ANGELIM, 2013). 
Ademais, Monteiro et al. (2011) acrescentam outros detalhes que a programação por LB oferece, que são o inventário, o $5 \mathrm{~W} 2 \mathrm{H}$ e os pacotes de trabalho, identificando-as graficamente conforme a Figura 1.

\section{Figura 1 - Identificação dos principais elementos da LB.}

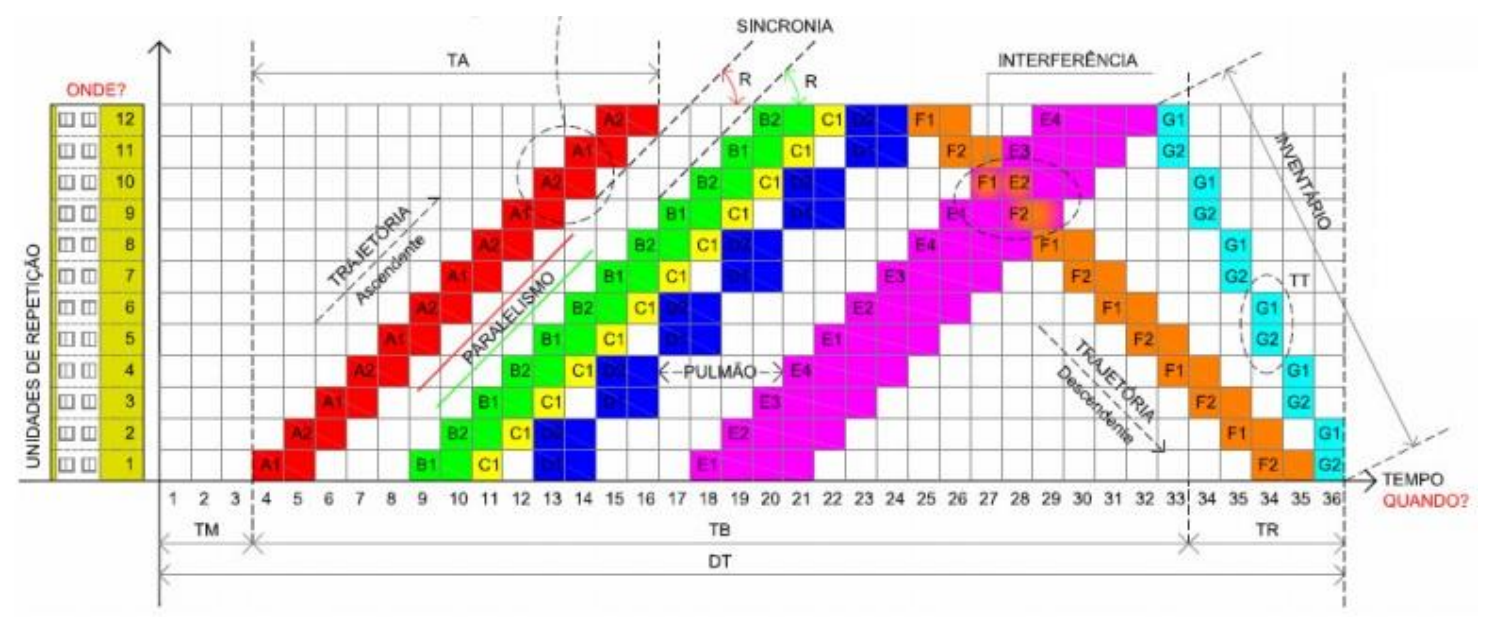

Fonte: Monteiro et al. (2011)

Diversos autores têm empreendido esforços na análise de suas implicações e desdobramentos para a programação de edifícios verticais, tais como Mendes Júnior e Heineck (1998), Mendes Júnior (1999), Lucko, Alves e Angelim (2013), dentre outros. Outras utilizações como a aplicação da LB em projetos de construção de rodovias, podem ser observadas nos trabalhos de Chrzanowski e Johnston (1986), Arditi e Albulak (1986), Harmelink e Yamin (2001).

Em comum, estes trabalhos relatam principalmente sobre a estabilidade da aplicação dos recursos, nivelamento da produção e facilidade para o gerenciamento visual da construção. Outras vantagens, como o efeito aprendizado, também são apresentadas devido à definição de um lote de produção que pode se repetir, proporcionando a oportunidade de aprendizado contínuo, aumento da qualidade e da produtividade na construção, mostrando como útil a aplicação desta técnica de planejamento.

\section{METODOLOGIA}

O presente estudo classifica-se como qualitativo cujos objetivos foram explorar e descrever (COLLIS; HUSSEY, 2005) a aplicação do método da LB em uma obra industrial. Para tal, utilizou-se do estudo de caso como estratégia de pesquisa (YIN, 2010) no qual o objeto de estudo é uma obra de um tanque de uma refinaria da Petrobras.

Primeiramente, realizou-se uma revisão bibliográfica sobre o planejamento de processos de produção, tanto para a construção de edifícios como para a construção de obras industriais. Conduziu-se, então, uma análise comparativa entre os elementos de planejamento das duas áreas pesquisadas.

Foram realizadas visitas ao setor de planejamento da refinaria Petrobras/Lubnor. O objetivo da primeira visita foi a coleta de dados e informações sobre a metodologia aplicada, atualmente, para o planejamento de obras internas da Petrobras/Lubnor. Já em um segundo momento, o objetivo foi a escolha da obra para a aplicação do estudo de caso. Após a escolha da obra, foram analisados os projetos e foi feita uma revisão bibliográfica sobre o tipo de obra, as suas etapas e a sua forma de execução. Para cada visita foi elaborado um questionário para a coleta de informações. 
Nesse estudo, a obra escolhida para a análise foi a construção de um tanque de armazenamento de CAP. Foram analisados os projetos, de forma que, primeiramente, fosse entendido a rede lógica de predecessoras desse tipo de obra.

Em seguida, partiu-se para a montagem da LB. Foi necessária a definição de um modelo simplificado para a obra, determinando as atividades que seriam consideradas para o modelo. Juntamente com a definição dos pacotes de trabalho, foram analisadas as restrições do projeto (ordem de execução e limitações construtivas), de forma que a elaboração da LB chegasse próxima da realidade.

\section{RESULTADOS}

\subsection{Caracterização do estudo de caso}

O projeto consiste na construção de um tanque de armazenamento da Petrobras/Lubnor, de teto fixo, com estrutura autoportante para o armazenamento de CAP (Cimento Asfáltico de Petróleo). A capacidade do tanque é de $3.400 \mathrm{~m}^{3}$ e possui dimensões de $17,17 \mathrm{~m}$ de diâmetro e $14,64 \mathrm{~m}$ de altura.

Segundo Barros (1998), tanques de armazenamento são equipamentos de caldeiraria pesada, sujeitos à pressão, aproximadamente atmosférica, destinados, principalmente, ao armazenamento de petróleo e de seus derivados. Estes são utilizados para armazenar vários tipos de produtos (matérias primas, insumos e produtos finais) em grandes quantidades. Os tanques podem ter variadas dimensões, formas, tipos, e podem ser constituídos por diversos materiais, sendo o mais comum o aço-carbono.

Os componentes típicos de um tanque de armazenamento convencional são: base, fundação, fundo, costado e teto, conforme a Figura 2.

Figura 2 - Descrição dos componentes de um tanque de armazenamento

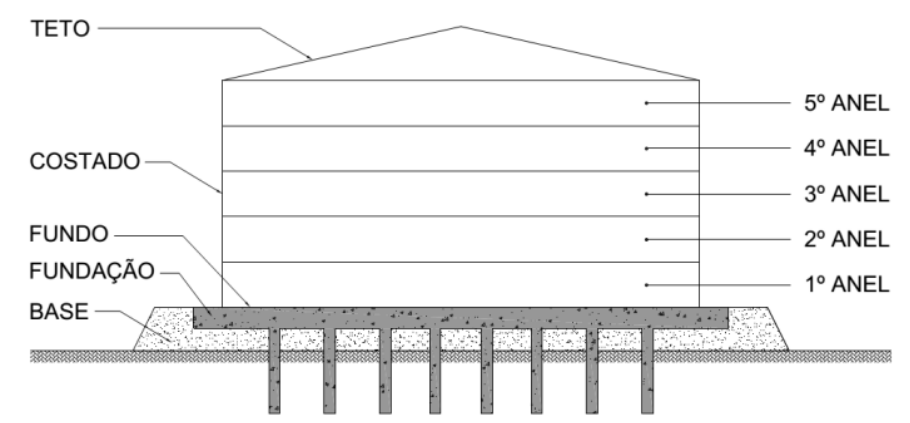

Fonte: Costa (2011).

Os tanques são classificados de acordo com o tipo construtivo do seu teto e a definição do tipo de teto é feita a partir do produto que será armazenado.

Para esse trabalho, algumas simplificações foram adotadas para a LB da construção do tanque. As atividades consideradas no modelo foram: fundação, montagem das chapas do fundo, montagem, pintura e isolamento térmico dos anéis do costado, montagem do teto, teste hidrostático. Atividades como bases para a tubulação, dique de contenção, proteção catódica, bases para plataformas, aterramento e colocação dos assessórios do tanque não foram consideradas para o modelo.

\subsection{Componentes do Tanque}

A Figura 3 apresenta as etapas executivas da edificação estudada. 


\section{Figura 3 - Construção do Tanque de CAP}
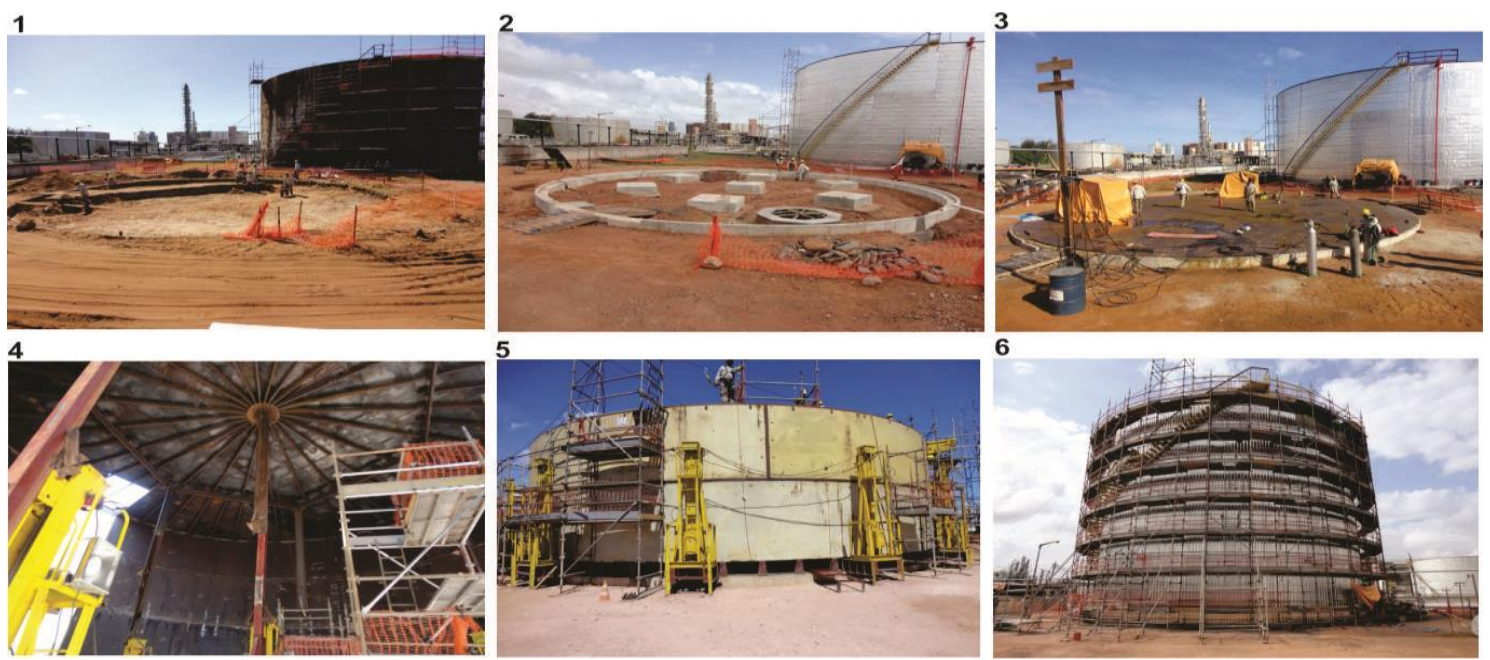

Fonte: Arquivo Petrobras/Lubnor (2013)

A etapa de execução da base do tanque refere-se à movimentação de terra inicial, conforme Figura 3, quadro 1. É nesta etapa que ocorreram as atividades de bota fora, reaterro e compactação do solo.

As fundações são compostas por uma cinta circunferencial em concreto armado sob o costado, de acordo com a Figura 3, quadro 2. Foram consideradas as seguintes tarefas resumidas: escavação, compactação de base e lastro de concreto magro, execução de formas e montagem da armadura, concretagem da estrutura de concreto, execução de sete sapatas para suporte do teto (escavação, formas, armaduras e concretagem).

O fundo é formado por tiras de chapas de aço superpostas, unidas através de soldas de filete, conforme Figura 3, quadro 3. Foram consideradas as seguintes tarefas resumidas: posicionamento, soldagem das chapas, inspeções e ensaios.

A próxima etapa de execução é a do costado, composto de chapas unidas por solda. A Figura 3, quadro 5, mostra a montagem dos anéis com a utilização de macacos hidráulicos. O costado é constituído por 6 anéis, cujas tarefas consideradas foram: posicionamento das chapas, soldas verticais, soldas horizontais e inspeções e ensaios.

A estrutura interna é formada por coluna central, coluna intermediária, coroa central, vigas radiais principais, vigas radiais secundárias, vigas transversais, cantoneira de apoio, conforme mostrada na Figura 3, quadro 4. Foram consideradas as seguintes tarefas resumidas: montagem de estrutura, montagem de chapas de teto, soldagem, inspeções e ensaios.

O tanque foi testado com coluna d'água após execução de todos os serviços de manutenção, soldagem e pintura. A finalidade do teste hidrostático é avaliar o tanque quanto a sua resistência estrutural e a sua estanqueidade. As atividades para esse teste englobam o enchimento em quatro etapas do tanque, sendo as etapas de $25 \% / 50 \% / 75 \% / 100 \%$ de água. Aguardou-se $24 \mathrm{hs} \mathrm{em} \mathrm{cada} \mathrm{etapa} \mathrm{e} \mathrm{esvaziou-se} \mathrm{o} \mathrm{tanque.}$ De acordo com dados coletados na Petrobras/Lubnor, a média de duração para o teste é de 10 dias.

No tanque em estudo não houve pintura externa completa, pois este possui isolamento térmico. Nesse caso, a pintura é feita apenas nos locais aonde foram executadas as soldas. Foram consideradas as seguintes tarefas resumidas: montagem de andaimes, jateamento, pintura interna e externa nas soldas do tanque e desmontagem de andaimes. Esse serviço abrange além da aplicação da tinta, as operações de inspeção visual, 
limpeza, tratamento da superfície, aplicação da tinta de fundo, aplicação de tinta de acabamento e controle de continuidade de película. O seu interior não precisa de proteção, salvo as estruturas de suporte e as chapas no teto, onde é aplicada uma pintura primária com a função de evitar a sua degradação com acabamento em tinta de esmalte acrílico branco.

A finalidade do isolamento térmico é diminuir a perda de calor nos tanques de produtos aquecidos. O tanque em estudo contempla essa etapa, por conta do tipo de material armazenado, de acordo com o quadro 6 da Figura 3.

\subsection{Montagem do Tanque de Armazenamento}

A montagem do tanque de armazenamento é feita "de cima para baixo", utilizando macacos hidráulicos, conforme ilustrado na Figura 4. Primeiro é feita a fundação, depois monta-se o fundo do tanque. Monta-se, no solo, o teto e o anel superior do costado (conforme quadros 1, 2 e 3 da Figura 4). Com a ajuda de macacos hidráulicos, posicionados em torno do perímetro do costado do tanque, suspende-se o anel superior e o teto até que a altura permita a montagem do próximo anel (quadros 4 e 5 da Figura 4).

Assim é feita a montagem de forma sucessiva até o anel 1, que é o último a ser montado (conforme quadro 6 da Figura 4). Dessa forma, a operação de soldagem é sempre realizada a uma altura baixa em relação ao solo, correspondente à largura da chapa do costado. Assim, evita-se a necessidade de andaime e de trabalho em altura.

\section{Figura 4 - Montagem do Tanque de Armazenamento}

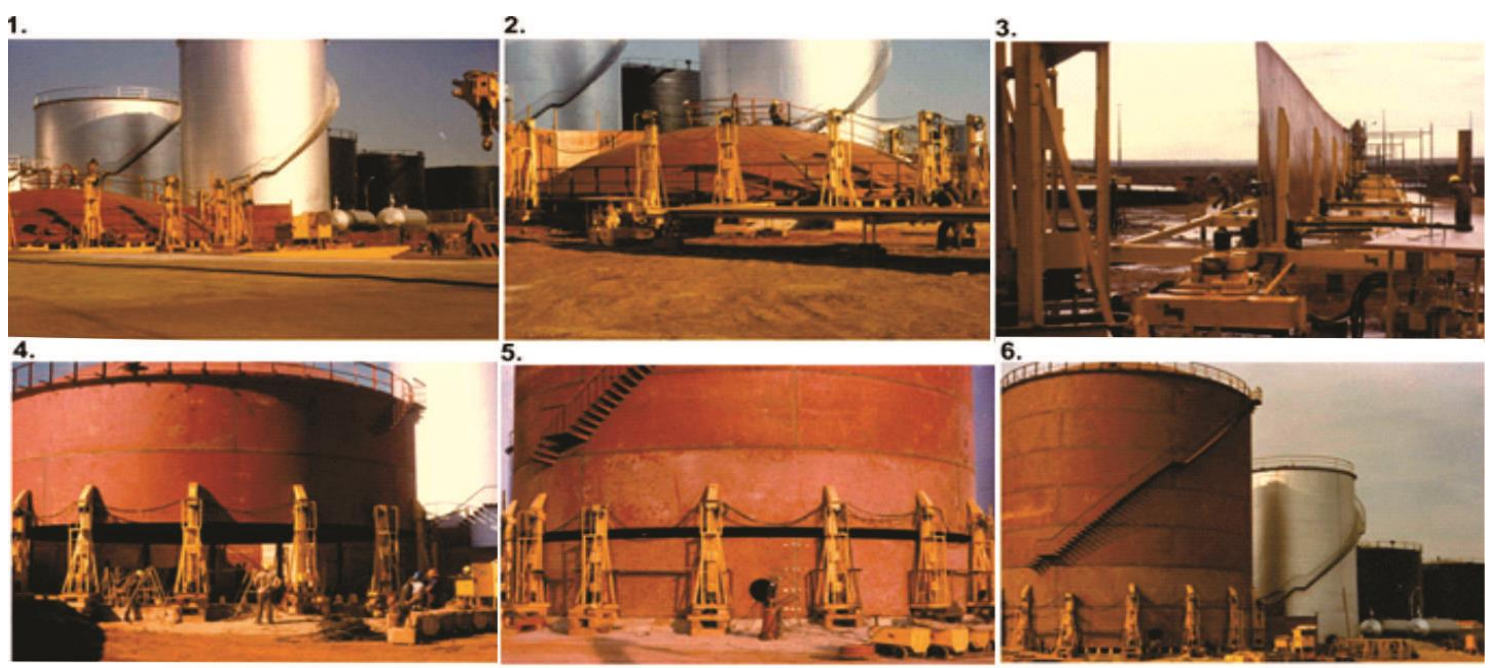

Fonte: Apostila Montagem (2013)

\subsection{Aplicação do método da Linha de Balanço na execução do projeto}

Para esse trabalho foram elaboradas duas LB. O primeiro estudo foi preparado supondose a construção de 1 tanque de armazenamento. Dessa forma, retrata-se o caso da Petrobras/Lubnor. Em seguida, foi feito um segundo estudo simulando a construção de 3 tanques de armazenamento. Dessa forma, pode-se avaliar a eficiência do método para a construção de mais de 1 tanque.

Para efeito de estudo, a construção do tanque foi separada em seis etapas: (1) Fundação; (2) Fundo; (3) Costado; (4) Teto; (5) Pintura; (6) Teste Hidrostático. Tentou-se definir uma unidade repetitiva para cada etapa, porém não foi possível definir esta unidade repetitiva para o teto e para o teste hidrostático. Em seguida, foram definidos os pacotes 
de trabalho e a elaboração da EAP (Estrutura Analítica de Projeto), conforme a Figura 5 .

\section{Figura 5 - Estrutura Analítica do Projeto}

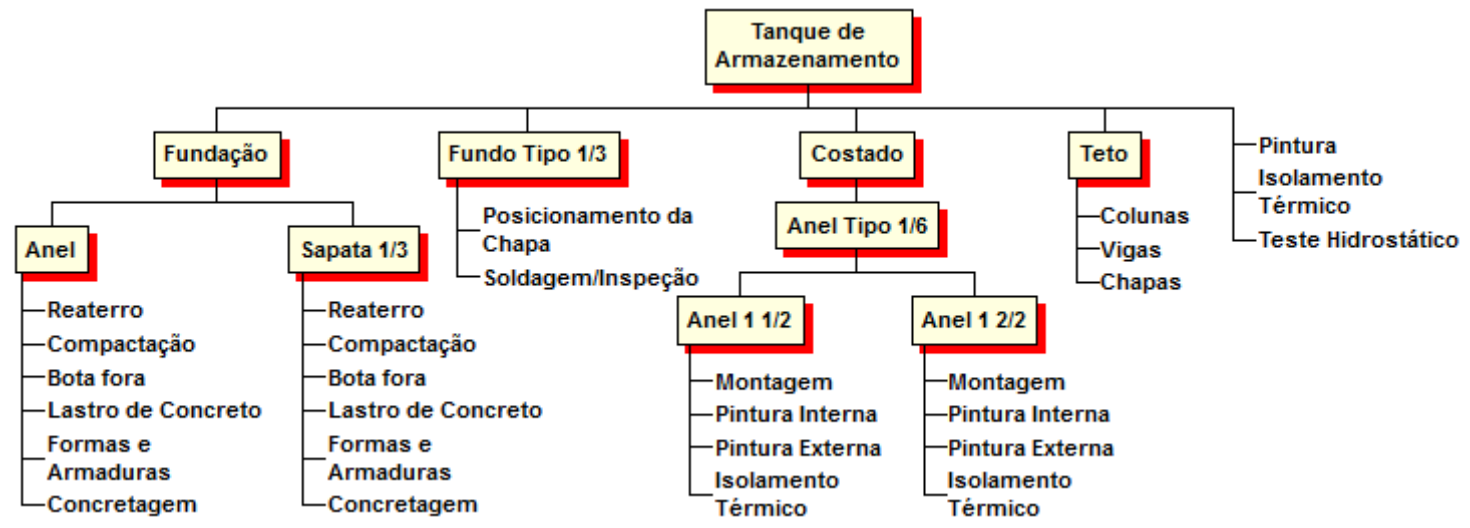

Fonte: dos autores.

A unidade de repetição para a Fundação foram os blocos de pacotes que possuem as mesmas atividades: o Anel e a Sapata. A Nomenclatura "Sapata 1/3" significa que serão feitos três pacotes de sapatas iguais. O fundo foi dividido em 3 partes, onde cada parte possui as atividades de posicionamento de chapas, soldagem e inspeção, que são suas unidades de repetição. Para o Costado a unidade de repetição adotada foi o anel. Os anéis, primeiramente foram divididos ao meio (conforme nomenclatura "Anel 1 1/2" e "Anel 1 2/2"). Em seguida, foram feitos seis pacotes com a nomenclatura "Anel 1/6", sendo a fração " $1 / 6$ " referente à posição da altura do anel no tanque.

Para a determinação da duração dos pacotes de trabalho, foi necessário identificar os índices de produtividades para cada atividade. Por falta de informação, alguns índices tiveram que ser estimados e/ou pesquisados na literatura. Para a etapa de trabalhos em aço, foram considerados os índices publicados por Almeida (2006) e Simonsen (2004). Os índices de produtividade referentes à etapa civil foram coletados no mercado em empresas de planejamento de obras. A Tabela 1 apresenta as produtividades para cada etapa da obra, de acordo com as fontes indicadas.

Tabela 1 - Tabela de índices de produtividade

\begin{tabular}{lcc}
\hline \multicolumn{1}{c}{ Etapa } & Produtividade & Fonte \\
\hline Montagem/Soldagem do Anel & $90 \mathrm{Hh} / \mathrm{T}$ & SIMONSEN (2004) \\
\hline Montagem Base - Chapas & $64 \mathrm{Hh} / \mathrm{T}$ & ALMEIDA (2006) \\
\hline Montagem Teto - Estrutura (colunas e vigas) & $300 \mathrm{Hh} / \mathrm{T}$ & ALMEIDA (2006) \\
\hline Montagem Teto - Chapa Lisa & $0,214 \mathrm{Hh} / \mathrm{kg}$ & ALMEIDA (2006) \\
\hline Pintura Interna / Externa & $2 \mathrm{Hh} / \mathrm{m}^{2}$ & ALMEIDA (2006) \\
\hline Escavação & $5,6 \mathrm{~m}^{3} / \mathrm{dia}$ & AVAL \\
\hline Formas / Aço & $6,4 \mathrm{~m}^{2} /$ dia & AVAL
\end{tabular}

Fonte: dos autores.

Segundo Simonsen (2004), em torno de 35\% dos homens-horas são consumidos no manuseio, na montagem e no ajuste das chapas e $65 \%$ na sua soldagem. Assim, a produtividade para o isolamento térmico foi estimada em 4 dias por anel. 
Com esses índices e quantidades de serviço, as durações foram calculadas para cada atividade bem como a mão-de-obra necessária para a sua execução e logo em seguida foi montada a LB para as duas situações propostas.

A Figura 6 representa a LB completa para 1 tanque de armazenamento. Pode-se observar que todas as atividades foram programadas em fluxo contínuo.

Figura 6 - LB 1T

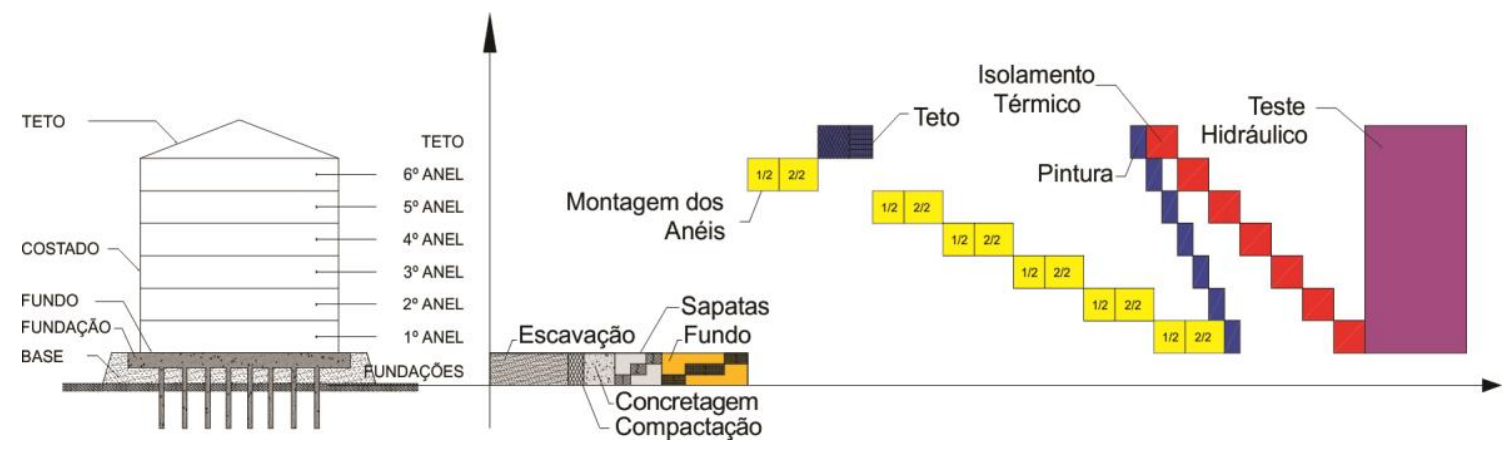

Fonte: dos autores.

Pode-se observar também, a trajetória não tradicional da construção do tanque. Nas etapas de pintura e de isolamento térmico os anéis também foram separados em 2 partes. Dessa forma, foi preciso montar os andaimes para executar o serviço apenas uma vez simplificando o processo de produção e proporcionando economia de tempo para atividade.

Para a LB 3T, o aproveitamento de equipes é mais intenso. A Figura 7 exibe a LB completa para 3 tanques. Nesse caso, é possível aproveitar as equipes de um tanque para o outro. Por exemplo, a montagem do teto, que antes não era uma unidade de repetição, passou a ser.

Figura 7 - LB 3T

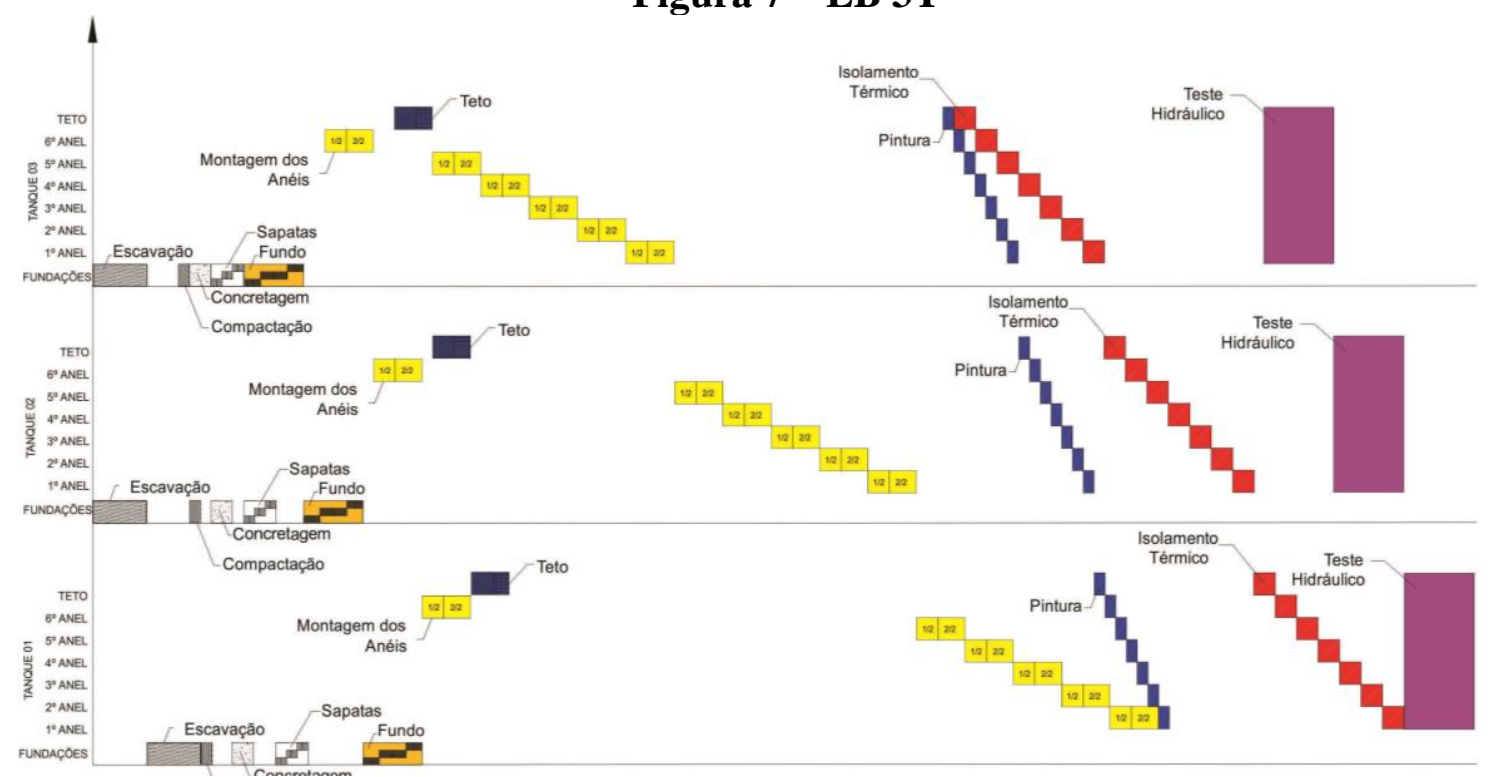

Fonte: dos autores.

Outra atividade importante que passou a ser contínua foi o teste hidrostático, que, dessa forma, traz o aproveitamento da equipe, como também da água utilizada nos testes para os 3 tanques. Dessa forma, percebeu-se que o fluxo contínuo é mantido por mais tempo 
multiplicando-se, desta forma, os benefícios evidenciados por essa técnica de planejamento. Assim, conseguiu-se simular várias estratégias dos serviços adotados, de forma a analisar as melhores possibilidades para a execução da obra.

Observa-se a reutilização da equipe de montagem dos anéis (representados pelos quadrados em amarelo). Para essa análise, pode-se observar, por exemplo, a alteração na quantidade de equipes, possibilitando o aproveitamento da mão de obra. É possível perceber o aproveitamento completo de equipes. Diferente do que seria, caso a construção fosse realizada em série.

\section{CONCLUSÕES}

O presente trabalho apresentou a aplicação da técnica de LB em uma obra de uma Indústria Petroquímica possibilitando uma análise de sua pertinência. Como resultado, foi possível realizar uma caracterização do processo construtivo, a proposição de uma estrutura analítica de projeto, o levantamento de índices de produtividades e a aplicação do método no caso estudado.

A maior dificuldade encontrada foi a definição do lote de produção repetitivo o que pode inviabilizar a utilização desta técnica. Encontrada a unidade de repetição, os autores acreditam que o uso da Linha de Balanço para obra estudada agregou relevantes melhorias para o planejamento da mesma. O gerenciamento da obra também pode ser facilitado pela forma visual que a Linha de Balanço oferece, proporcionando uma interpretação fácil e rápida do planejamento da obra, além de aumentar a transparência do processo de construção.

Com a LB, a continuidade das tarefas é estimulada. Além de que, pode-se proporcionar um aumento na produtividade, por conta do efeito aprendizado, devido à repetição da execução de lotes semelhantes pelas equipes. Assim, o entendimento do serviço torna-se cada vez mais claro impactando positivamente, também, na qualidade dos serviços.

Por fim, destaca-se que a técnica de Linha de Balanço pode ser viável em obras industriais, desde que se encontre uma unidade de repetição que justifique sua utilização. Encontrada a unidade de repetição, a elaboração da EAP se torna simples e trará mais benefícios na execução de mais tanques.

Como sugestão para próximos trabalhos, recomenda-se analisar se o método adotado é viável financeiramente no quesito quantidade de equipamentos solicitados para a execução do projeto, ou seja, se a estratégia de ataque proporcionada pelo aproveitamento das equipes, que irá aumentar o prazo do projeto, é viável contra a redução da mobilização de equipamentos; Ampliar o número de atividades da LB desse estudo de caso, ou seja, incluir etapas de construção de acessórios dos tanques; Coletar a produtividade real dos trabalhadores da construção da indústria do petróleo; Testar a aplicabilidade do método da LB em outras obras industriais presentes em refinarias; Testar a aplicabilidade do método da LB em outros tipos de tanques ou com outro método construtivo; Comparar quantitativamente o método da LB com o método do Gráfico de Gantt.

\section{REFERÊNCIAS BIBLIOGRÁFICAS}

AGÊNCIA NACIONAL DO PETRÓLEO, GÁS NATURAL E BIOCOMBUSTÍVEIS (ANP). Anuário estatístico brasileiro do petróleo, gás natural e biocombustíveis. Rio de Janeiro: ANP, 2013.

ALMEIDA, J. Técnicas de planejamento e controle. Rio Grande: FURG - CTI, 2006. 
AL SARRAJ, Z. M. Formal Development of Line-of-Balance Technique. Journal of Construction Engineering and Management, V. 116, n.4, 1990.

ARDITI, D; ALBULAKI, Z. Line-of-Balance Scheduling in Pavement Construction. Journal of Construction Engineering and Management, V. 112, p. 441-424. 1986.

BARROS, S. M. Tanques de Armazenamento. Rio de Janeiro: Petrobras, 1998.

CARNEIRO, R. M. Proposta de método de gerenciamento de projetos baseado em escopo e comunicação: Estudo de caso em uma empresa de perfuração de poços de petróleo offshore. Projeto de Pós Graduação - MBA em Gerenciamento de Projetos. Niterói: UFF, 2009.

CHRZANOWSKI , E. N; JOHNSTON, D. W. Application of Linear Scheduling. Journal of Construction Engineering and Management. V. 112. p. 476-491, 1986

COLLIS, J; HUSSEY.R. Pesquisa em administração: um guia prático para alunos de graduação e pós-graduação. 2 Ed. Porto Alegre: Bookman, 2005.

COSTA, O. Inspeção de tanques de armazenamento. 2011. Apostila.

DAMCI, A.; ARDITI, D.; ASCE, M.; POLAT, G. Multiresource Leveling in Line-of-Balance Scheduling. Journal of Construction Engineering and Management. V. 139, n. 9, p. 11081116, 2013.

HARMELINK, D. J; YAMIN, R. A. Development and Application of Linear Scheduling Techniques to Highway Construction Projects. Publication FHWA/IN/JTRP-2000/21. J oint T ransportation Research Program, Indiana Department of T ransportation and Purdue University, W est Lafayette, Indiana, 2001. doi: 10.5703/1288284313176.

HEINECK, L. F. M. Dados básicos para a programação de edifícios altos por linha de balanço. Florianópolis, SC. In: Congresso Técnico-Científico de Engenharia Civil, Florianópolis, p. 167173, 1996.

LUCKO, G.; ALVES, T. D. C. L.; ANGELIM, V. L. Challenges and opportunities for productivity improvement studies in linear, repetitive, and location-based scheduling. Construction Management and Economics, April 2014, p. 1-20, 2013. Disponível em: <http://www.tandfonline.com/doi/abs/10.1080/01446193.2013.845305>. Acesso em: 23/5/2014

MENDES JUNIOR, R; HEINECK, L. F. M. Dados básicos para programação de edifícios com linha de balanço. In: VII Encontro Nacional de Tecnologia do Ambiente Construído, ENTAC. Anais... Florianópolis, 1998. 686-696p.

MENDES JUNIOR, R. Programação da produção na construção de edifícios de múltiplos pavimentos. Tese de Doutorado - Engenharia de Produção. Florianopolis: UFSC, 1999.

MONTEIRO, J. M. F; CRUZ, A. C. M; MOREIRA, K. M. D; CRUZ, L. T. G; MORORÓ, M. S. M; HEINECK, L. F. M. Identificação gráfica de elementos da Construção Enxuta no planejamento de obras com Linha de Balanço. In VII Simpósio Brasileiro de Gestão e Economia da Construção. Anais... Belém, PA: 2011.

RYDLEWSKI, C. Ação: A incrível trajetória do furacão Foster, um fenômeno meteorológico que está sacudindo a poeira da maior empresa do Brasil. Revista Época Negócios, São Paulo, n. 69, p. 80-97, nov. 2012.

SIMONSEN, O. Aumento da produtividade das empresas de construção e montagem com vistas à melhoria da competitividade da indústria nacional. ABEMI, 2004.

SOUSA, H.; MONTEIRO, A. Linha de Balanço: Uma nova abordagem ao planejamento e controlo na construção. In: FÓRUM INTERNACIONAL DE GESTÃO DA CONSTRUÇÃO, 2., 2011, Faculdade de Engenharia da Universidade do Porto. Anais.

SUHAIL, B. S. A; NEALE, R. H. CPM/LOB: new methodology to integrate CPM and Line of Balance. Journal of Construction Engineering and Management. V. 120, n. 3, p. 667-684, 1994.

YIN, R. K. Estudo de caso: planejamento e métodos. 4ed. Porto Alegre: Bookman, 2010. 